\title{
A FORMA E O CARÁTER DA VEGETAÇÃO NA RECONSTRUÇÃO PAISAGÍSTICA DO PASSEIO PÚBLICO'
}

\author{
THE SHAPE AND CARACTER OF THE VEGETATION IN THE LANDSCAPE RECONSTRUCTION \\ OF PASSEIO PÚBLICO
}

\begin{abstract}
TRINDADE, Jeanne Almeida da
Arquiteta Urbanista; Especialista em Planejamento Ambiental e Paisagístico; Mestre em Ciências da Arquitetura. Assistente da Fundação Parques e Jardins. Professora de Teoria e História do Paisagismo e Planejamento Paisagístico da Universidade Estácio de Sá. E-mail: jeannetrindade@superig.com.br
\end{abstract}

\section{RESUMO}

O Passeio Público da cidade do Rio de Janeiro é considerado o primeiro espaço livre público ajardinado do Brasil, destinado ao convívio social da população. Durante sua existência, alternou períodos de boa conservação com abandono de modo que, no início do século XXI, a prefeitura do Rio de Janeiro decidiu contratar o projeto e a obra de restauração do Passeio Público com a intenção de devolver à população este espaço revitalizado. Este trabalho tem a finalidade apresentar a metodologia utilizada para orientar as decisões de manutenção, remoção e replantio da vegetação deste importante jardim histórico brasileiro.

Palavras-chave: Restauração, jardim histórico, vegetação.

\begin{abstract}
The Passeio Público of Rio de Janeiro city is considered the first public space with a designed garden in Brazil, built for the social living of the population. During its existence it alternated in periods of good conservation and total abandon, in such a way that, in the beginning of the 21 st Century, Rio de Janeiro city council decided to contract the project and as well as the work of restoration of the Passeio Público with the intention of returning this space completely renewed to the population. This paper aims to present a methodology used to guide the maintenance decisions, removal and re-planting of the vegetation of this important Brazilian historical garden.
\end{abstract}

Key words: Restoration, historic garden, vegetation.

\section{Introdução}

O conceito de patrimônio cultural tem evoluído em todas as partes do mundo. Em 1968 foi criado no ICOMOS - Conselho Internacional de Monumentos e Sítios - um comitê específico para tratar de jardins históricos: o Comitê Internacional de Jardins e Sítios Históricos - ICOMOS/IFLA. Seus objetivos principais são: promover a defesa, a reabilitação, o conhecimento e a difusão do grande patrimônio cultural que são os jardins e os sítios históricos; estabelecer uma teoria e uma prática de restauração, através de uma legislação adequada; formar especialistas preparados para atuar na área de restauração de jardins históricos além de que, na formação do arquiteto paisagista, deve-se valorizar a análise dos jardins históricos, seu estudo, sua compreensão e sua comparação para constituírem a base e a semente dos jardins modernos ${ }^{2}$.

Como um dos frutos das atividades deste Comitê, foi redigida em 1981 a Carta de Florença ${ }^{3}$ que elabora as diretrizes de proteção para os jardins históricos, assim definidos: Um jardim histórico é uma composição arquitetônica e vegetal que, do ponto de vista da história ou da arte, apresenta, um interesse público. Como tal é considerado monumento ${ }^{4}$. As técnicas para restaurar jardins se orientam a partir das técnicas de restauração das obras arquitetônicas porém, como nos jardins um dos objetos a ser restaurado $\boldsymbol{\otimes}$ o vegetal $\boldsymbol{\otimes}$ é um ser vivo em constante modificação, 
é necessário estabelecer regras próprias para a restauração esses espaços, conforme elencado pela Carta de Florença ${ }^{e}$ :

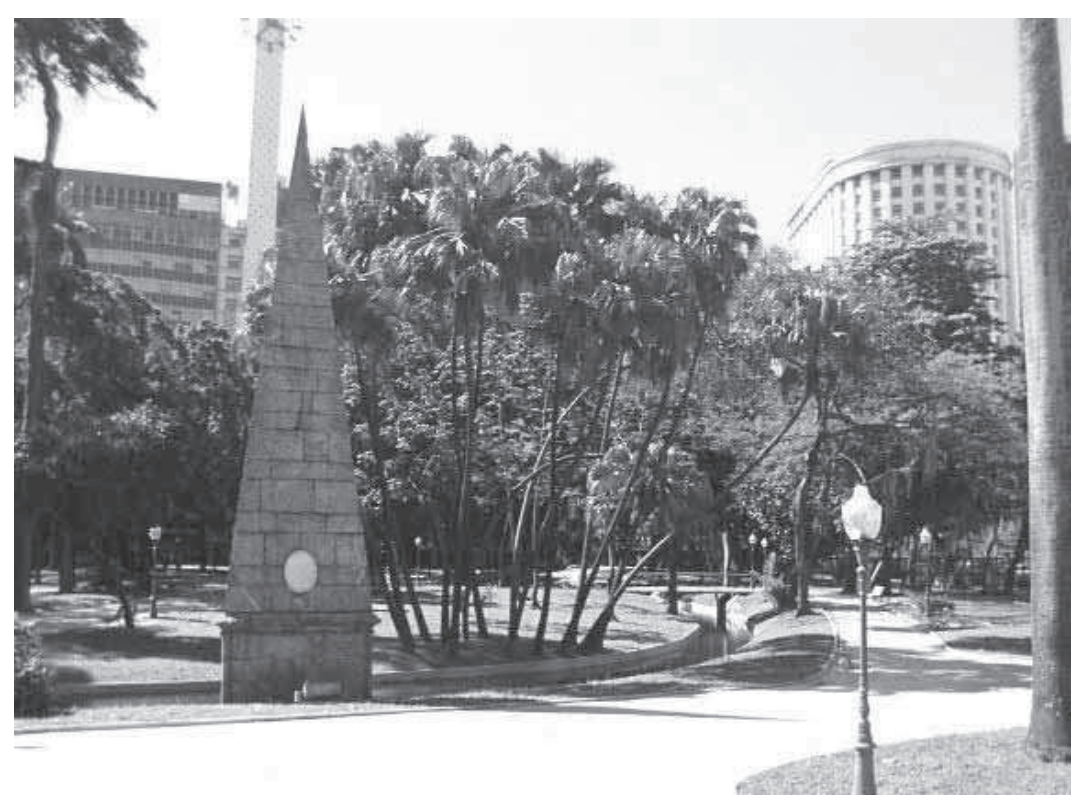

Figura 1: Conjunto formado pela pirâmide de granito, original do projeto de Valentim e palmeiras leque-da-china (Livistona chinensis) especificado por Glaziou Crédito: Foto da autora

As variações que os vegetais apresentam, ao longo de seu ciclo de vida, são determinantes no trabalho do paisagista, que busca adequar o desenvolvimento das plantas à utilização da população e ao projeto historicamente implantado. $O$ trabalho do restaurador deve resgatar formalmente as idéias do projeto a ser recuperado — os volumes, o jogo de cores e as texturas dos vegetais - sem a obrigação de retornar às espécies originalmente especificadas, devido às inúmeras modificações sofridas pelo conjunto ao longo dos anos. As decisões sobre a introdução ou substituição de espécies vegetais necessitam de pesquisas detalhadas, de modo a não descaracterizar a ambiência do jardim.

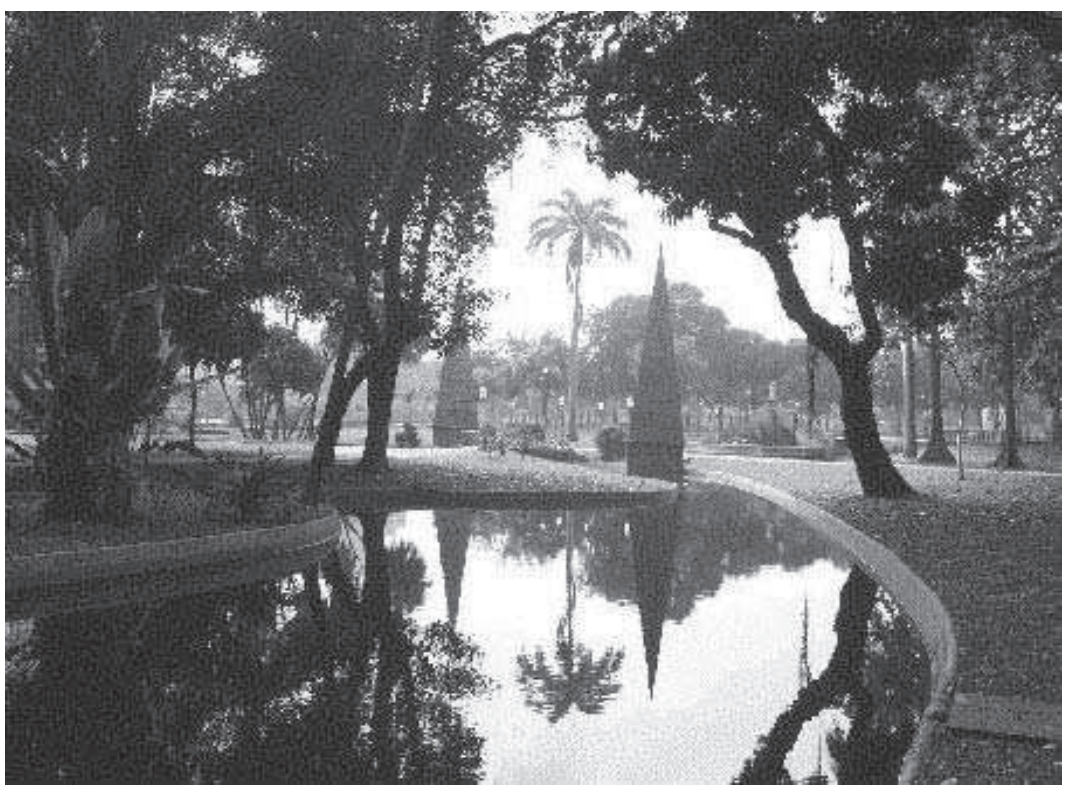

Figura 2: Vista parcial do lago tendo ao fundo as pirâmides e ponte ornamental. Destaque para as árvores e palmeiras que fazem parte da composição Crédito: Foto de Carlos Terra 
É necessário identificar quais são os elementos essenciais do jardim que conferem singularidade e importância para a comunidade. Qual a imagem simbólica e o significado do espaço para a população, para então executar um trabalho de restauração que irá mantê-las. Todo jardim histórico é um documento resultante das inúmeras intervenções ocorridas ao longo dos anos. O estado atual, antes dos trabalhos de restauração, apresenta a forma com que este bem foi conservado, avaliado, corrigido, abandonado e continuamente readaptado para a utilização das sociedades de diferentes épocas. Os trabalhos de restauração devem possibilitar ao usuário decifrar as diferentes fases do jardim e, só devem ser considerados problemáticos os acréscimos que prejudiquem a leitura da unidade do ambiente.

\section{Breve histórico do passeio público}

A construção do Passeio Público (1779-1783) foi uma decisão do vice-rei D. Luis de Vasconcellos e Souza e teve como autor Valentim da Fonseca e Silva - o Mestre Valentim -, mais conhecido por seu trabalho como escultor e entalhador. Esse jardim foi implantado por intermédio do aterramento da Lagoa do Boqueirão e concebido sob a influência dos jardins clássicos dos séculos $\mathrm{XVI}$ e XVII, e das idéias iluministas de crença no progresso por intermédio das realizações humanas. Em 1860, o paisagista francês Auguste Glaziou em conjunto com o brasileiro Francisco José Fialho apresentam ao Imperador do Brasil uma proposta para a conservação deste espaço pelo período de dez anos. Com a aprovação do proposto, o Passeio Público é submetido a uma grande reforma onde poucos elementos do projeto original foram mantidos e, o traçado retilíneo existente, substituído por caminhos sinuosos, canteiros assimétricos e recantos pitorescos, de modo a atender ao ideal romântico da época, tão bem representado pelos jardins paisagísticos ingleses do século XVIII. Durante a primeira metade do século XX, vários equipamentos de lazer foram inseridos neste jardim com o objetivo de valorizar o local e proporcionar a seus freqüentadores maiores possibilidades de prazer.

\section{Metodologia adotada}

O plano de manejo para a vegetação do Passeio Público do Rio de Janeiro foi elaborado por uma equipe multidisciplinar composta pelos seguintes profissionais: Carlos Fernando Delphin (IPHAN), Carlos Terra (UFRJ), Jeanne Trindade (FPJ), Mário Sophia (consultor da FB) e Miguel Gastão (Conselho Municipal de Patrimônio), a pedido da fiscalização das obras de restauração do Passeio Público executados em 2004. Em 2001/2002, a empresa Ópera Prima desenvolveu o projeto paisagístico porém, devido ao intervalo entre o projeto e o início das obras e as novas informações obtidas durante este período, os gestores da intervenção entenderam que o projeto necessitava de algumas adaptações.

A metodologia seguida pelo Grupo de Trabalho foi a seguinte:

- Verificação e atualização do inventário florístico do Passeio Publico apresentado pela Ópera Prima contendo a identificação das espécies, dados dendrométricos e sugestão de manejo.

A partir deste levantamento verificou-se que o Passeio Público teve uma conformação florística bastante variada ao longo da sua existência contendo, atualmente, poucos vegetais que poderiam ser atribuídos à intervenção de Mestre Valentim de acordo com as pesquisas realizadas por FARAH, I. M. C. . Com relação ao projeto de Auguste Glaziou foi encontrada uma parcela significativa de vegetação descrita no Relatório apresentado à Assembléia Geral pelo Ministro e Secretário de Estado dos Negócios da Agricultura, Comércio e Obras Públicas João Ferreira de Moura (Brazil, Imprensa Nacional, Rio de Janeiro, 1885) sobre o "Jardim da Praça da Acclamação (atual Campo de Santana) e Passeio Público" que indica as principais espécies utilizadas pelo paisagista nesses locais. Também foram encontrados alguns vegetais dispersos plantados, aparentemente, de maneira aleatória durante o século XX. 
De posse dessas informações, a orientação foi a de privilegiar o projeto de Auguste Glaziou por ser este a referência mais marcante encontrada, mantendo as possíveis contribuições remanescentes do Mestre Valetim e os exemplares significativos do século XX que não comprometessem a singularidade da obra de Glaziou.

- O segundo passo metodológico foi visitar diferentes projetos de Glaziou, no município do Rio de Janeiro e cidades vizinhas, para perceber qual a linguagem formal e de especificação vegetal características desse artista. Foram vistoriados os Parques São Clemente, Friburgo (1871); Quinta da Boa Vista, Rio de Janeiro (1874); Campo de Santana, Rio de Janeiro (1880) e a Casa de Petrópolis Instituto de Cultura, Petrópolis (1884). Também foram visitados alguns jardins executados durante a segunda metade do século XIX, tais como: Parque Mariano Procópio, Juiz Fora (1860); Palácio do Catete, Rio de Janeiro (1860) e Casa de Rui Barbosa, Rio de Janeiro (1879).

- Foi realizado um levantamento iconográfico do período entre 1860 e 1910 e comparado com o estado atual do Parque.

\section{Plano de manejo por questões históricas}

\section{O bambuzal}

O primeiro elemento vegetal que chamou a atenção do Grupo de Trabalho foi uma extraordinária touceira de bambu, localizada na frente do Portão Monumental, no eixo de ligação do Portão à Fonte dos Amores. Esta touceira possuía uma beleza plástica muito marcante devido, principalmente, as suas dimensões (aproximadamente de $50 \mathrm{~m}^{2}$ de extensão por $7 \mathrm{~m}$ de altura).

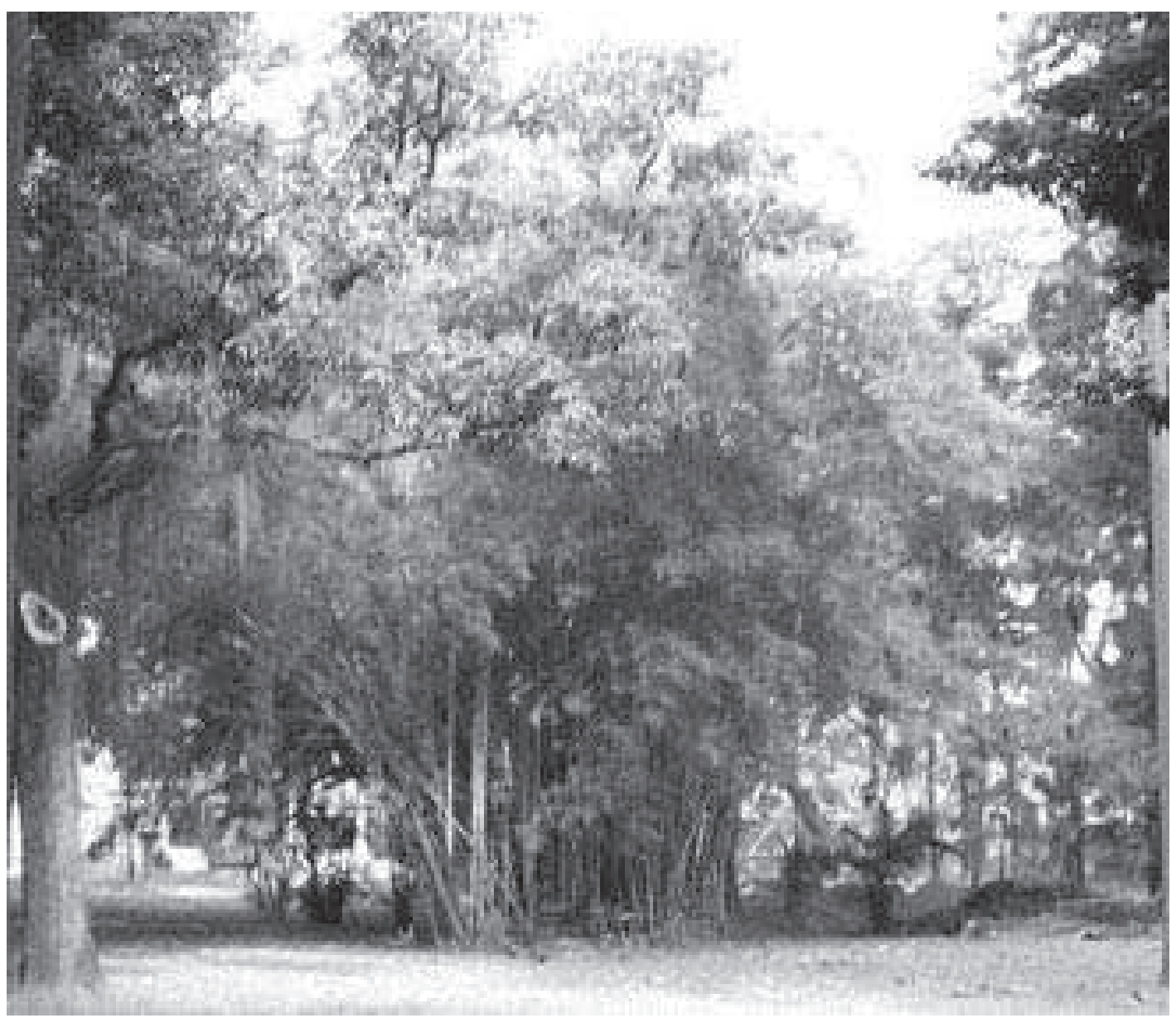

Figura 3: Bambuzal localizado no eixo entre o Portão Monumental e a Fonte dos Amores

Crédito: Foto de Carlos Terra 
Observando a planta atribuída a Glaziou, não foi verificada a presença desta mancha vegetal, mantendo-se livre de obstáculos o eixo longitudinal proposto por Valentim; fato esse comprovado analisando as fotos de Klumb (c. 1860) e Stahl (c. 1862). Por esse desenho, ao ultrapassar o Portão Monumental, o freqüentador percebe a existência de "algo" no final do jardim (parcialmente oculto por um arbusto) e é convidando a percorrer o jardim através dos caminhos sinuosos em direção à Fonte dos Amores.

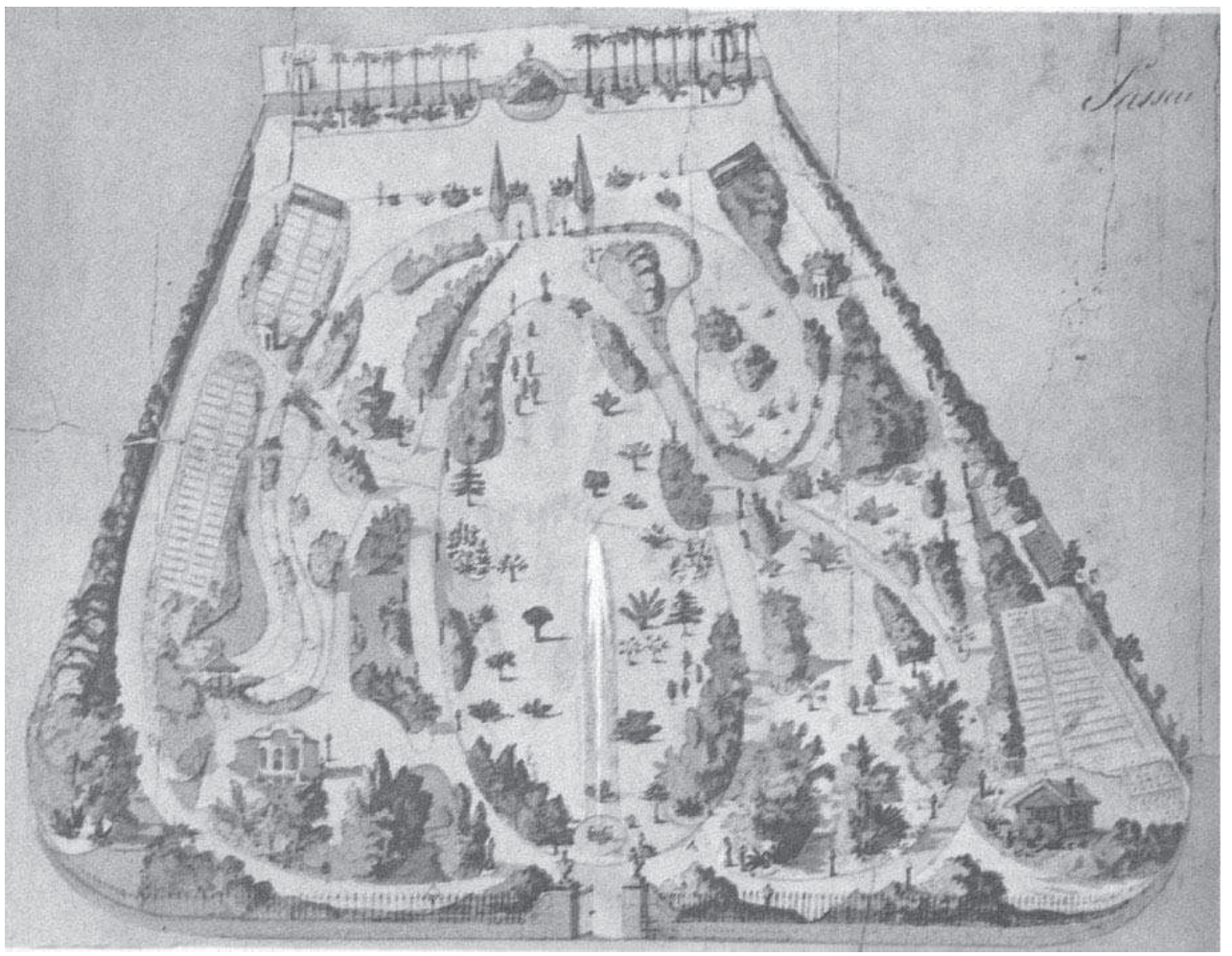

Figura 4: Planta do passeio público do século XIX. Desenho atribuído a Auguste Glaziou Crédito: Biblioteca Nacional, RJ

Entretanto, em visitas aos parques elaborados por Glaziou, como o Campo de Santana, Quinta da Boa Vista e Parque São Clemente, encontramos a presença de bambus na composição desses espaços. No citado Relatóriog, também, estão relacionadas cinco espécies diferentes de bambus e, analisando as fotos de Malta do início do século XX, verificamos a presença de uma vegetação muito semelhante a bambus plantada próxima ao Aquário (1904-1938). Teriam esses bambus se deslocado naturalmente até o canteiro central, o que seria possível dada a natureza da sua propagação? Não foi possível comprovarmos. Diante dessas informações, a indicação foi a de transplantar a touceira de bambu existente no canteiro central e replantá-la nos locais sugeridos pelas fotos de Malta, bem como sugerir o transplante de duas pequenas árvores de pau-brasil (Caesalpinea echinata) plantadas no eixo imaginário, para deixá-lo livre dos elementos que dificultavam a visualização da Fonte dos Amores.

\section{O espaço da Fonte dos Amores}

A Fonte dos Amores, tanto no projeto de Valentim como no de Glaziou, funciona como o ponto focal do jardim gerando um espaço de aconchego e recolhimento delimitado pelos planos formados pela própria fonte, pelas pirâmides e pelas grades de fechamento. No desenho atribuído a Glaziou, dos lados da Fonte, verificamos uma aléia de palmeiras intercaladas por vegetação de médio porte. Nas fotos de Klumb (c.1860) e Leuzinger (c.1860) percebemos que foram plantados dois tipos de palmeiras de forma intercalada, um com folhas pinadas e outro com folhas em forma de leque. 
No levantamento local, de um lado da Fonte, encontramos uma aléia contendo seis paus-rei (Pterygota brasiliensis), uma munguba (Pachira aquatica) e uma palmeira imperial (Roystonea oleracea) e do outro lado, uma aléia com uma palmeira imperial (Roystonea oleracea), um pau-rei (Pterygota brasiliensis) e dois paus-ferro (Caesalpinea ferrea). Quando foram plantadas essas árvores? A iconografia entorno de 1860 só revelava palmeiras no local. Acreditamos que as mesmas tenham sido plantadas depois de 1937, após a demolição do Theatro Cassino, cujos vestígios arqueológicos e as plantas cadastrais da época indicam que a edificação ocupava o local dessas árvores.

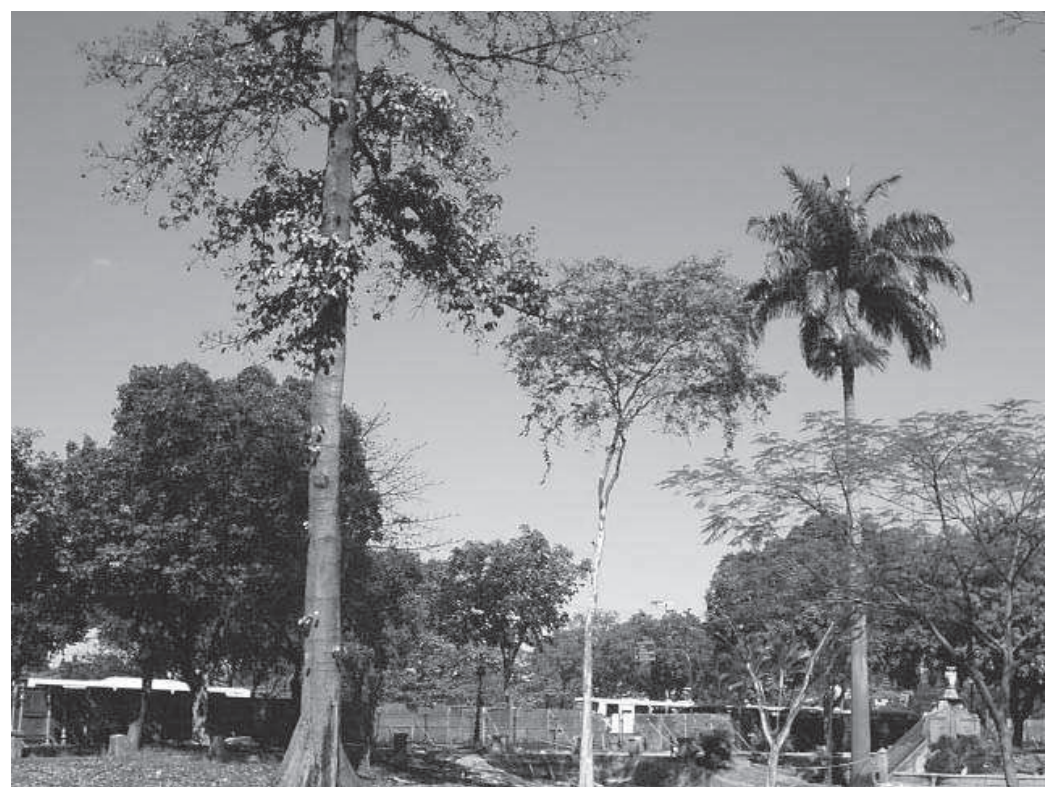

Figura 5: Aléia formada por pau-rei, paus-ferro e palmeiras imperiais Crédito: Foto da autora

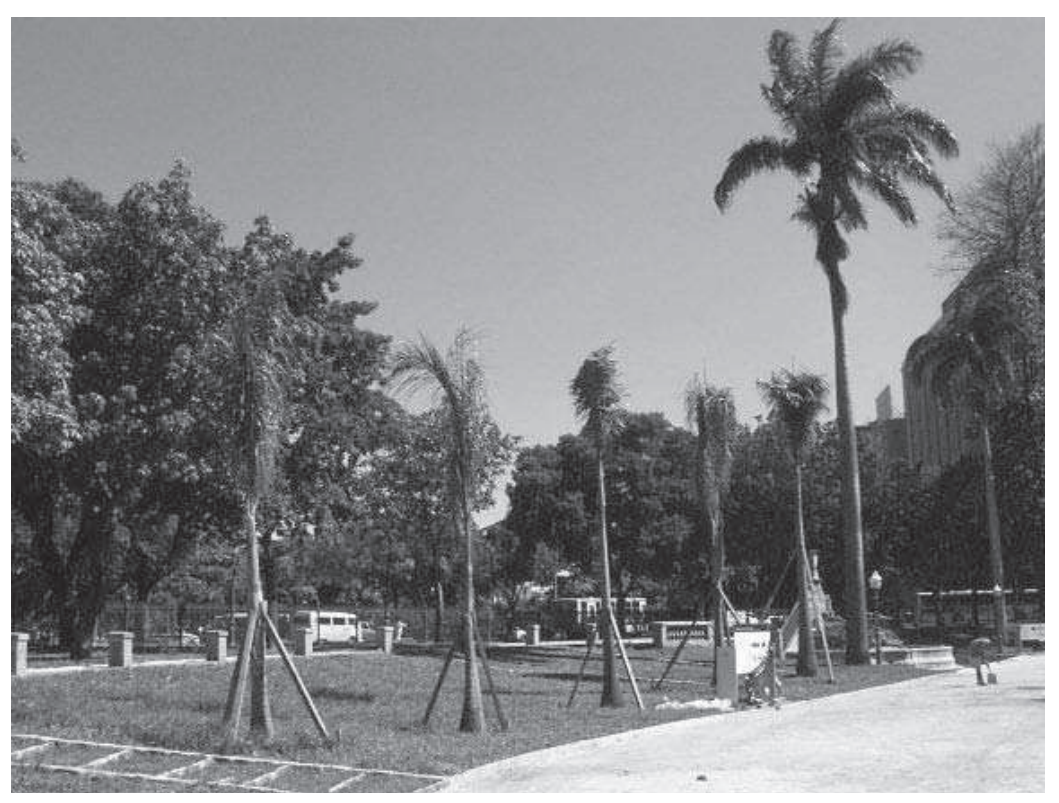

Figura 6: Nova aléia de palmeiras imperiais plantada após as obras de restauração

Crédito: Foto da autora

A fim de apresentar diferentes épocas do Passeio Público e manter uma unidade nos planos delimitadores do espaço da Fonte dos Amores, a sugestão do Grupo de Trabalho foi a de conservar intacta a aléia formada pelos paus-rei (Pterygota brasiliensis) e palmeira imperial (Roystonea 
oleracea), removendo o pau-rei (Pterygota brasiliensis) e os paus-ferro (Caesalpinea ferrea) da outra aléia e indicando o plantio de 6 palmeiras imperiais (Roystonea oleracea) e 6 exemplares de sabal-anão (Sabal minor) alternadamente. Apesar de não podermos afirmar ter sido esta a escolha de Glaziou, acreditamos que o conjunto formado dois tipos de palmeiras de formas de folhas e alturas diferentes (conforme o desenho atribuído ele) estabelece o objetivo pretendido. A escolha das espécies foi determinada pela existência de um remanescente de palmeira imperial (Roystonea oleracea) - palmeira de grande porte com folha pinada - e a espécie sabal-anão (Sabal minor) - palmeira de pequeno porte com folha em forma de leque - constar na relação

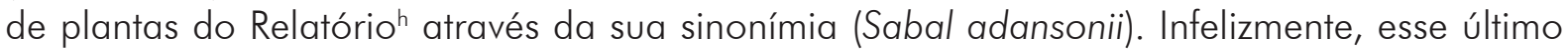
grupo de palmeiras ainda não foi plantado.

Complementado o plano delimitador desse espaço pelas Pirâmides, o Grupo indicou o replantio das touceiras de palmeira-ráfia (Rhapis excelsa) dos lados das Pirâmides, que haviam sido depredadas pela ação de fogo. Essa palmeira foi largamente utilizada por Glaziou em outros projetos e consta no Relatórioi por sua sinonímia (Rhapis flabelliformis).

\section{Os arbustos}

A construção de um jardim romântico não se limita ao campo visual. As qualidades de temperatura, textura e som de um ambiente, em união com as impressões olfativas e gustativas proporcionam ao espectador uma sensação que o envolve por completo. Dentro desta forma de composição, os arbustos assumem uma posição de destaque, pois da maneira que são reunidos - através de alternância de cheios e vazios; dos contrastes de formas, volumes, aromas, texturas, tons e cores - se constroem os elementos de grande valor dos projetos românticos: a surpresa, a dinâmica, a assimetria, a expectativa e o mistério.

No Passeio Público, foram utilizados arbustos de grande variedade, conforme pode ser observados em fotos antigas porém, os arbustos encontrados durante a obra de restauração eram muito poucos. Provavelmente, na medida em que esses arbustos foram morrendo, não houve um planejamento para seu replantio. Recuperar as potencialidades do uso de diferentes tipos de arbustos, sem prejudicar a segurança do espaço, foi uma preocupação constante. A orientação foi o posicionamento dos novos arbustos junto ao gradil sem a formação de uma massa contínua; replantio nos pontos de interesse visual como pontes e pedras falsas e, colocação atrás de alguns bancos para funcionar com plano de fechamento visual da cidade.

Houve uma grande dificuldade em conseguirem mudas saudáveis, encorpadas, que constassem do Relatórioi e dentro dos recursos destinados na obra para esse fim. Diante desta limitação, algumas espécies relacionadas foram: Clerodendron fragrans, Gardenia jasminoides (Sin.: Gardenia florida), Medinilla magnifica, Pandanus utilis, Thumbergia erecta (Sin.: Meyenia erecta), todas produzidas no horto municipal. Houve uma preferência para sugestão de plantas perfumadas como forma de proporcionar aos freqüentadores uma sensação agradável através do olfato.

\section{As plantas de cobertura}

O Passeio Público possuía, antes das obras de recuperação, uma grande quantidade de singônio (Syngonium angustatum) utilizado como cobertura do solo. Esta espécie não consta no Relatório de plantas utilizadas por Glaziou, porém, atualmente é muito freqüente em alguns parques desse autor, como no Campo de Santana e Quinta da Boa Vista. Acreditamos que, devido a sua rusticidade e facilidade de propagação, essa espécie tenha sido introduzida por antigos gestores públicos, em substituição a grama que morria por insuficiência de luz. Contudo, o volume proporcionado pelo plantio de singônio é muito maior do que o volume da grama, além da forma de suas folhas ser completamente diferente. Outra característica dessa planta é a capacidade de utilizar os troncos das árvores como suporte, criando uma cortina vegetal ao seu redor. 


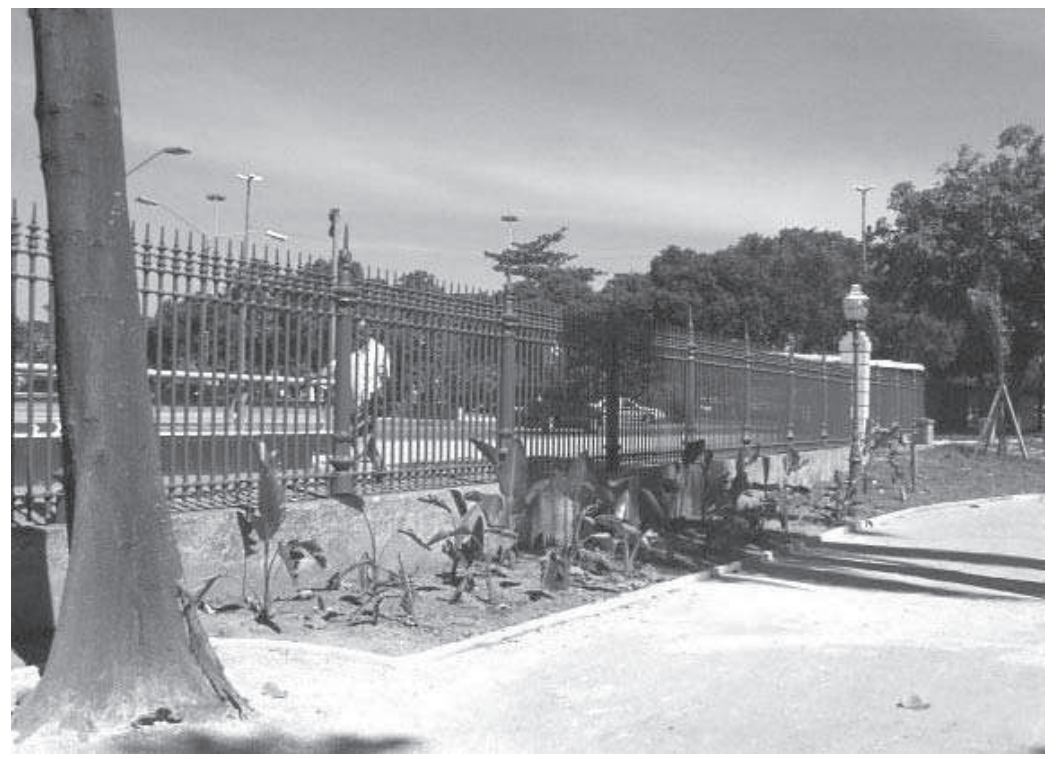

Figura 7: Plantio de arbustos próximos às grades existentes Crédito: Foto da autora

A despeito da beleza plástica que essa composição gera, a presença de singônio nos troncos das árvores produz um aumento de umidade que, em árvores antigas ou frágeis, pode favorecer ao aparecimento de fungos e bactérias prejudiciais à saúde do vegetal. Por esses motivos, entendeu-se ser o mais adequado a retirada dessa vegetação, inclusive dos troncos das árvores revelando a beleza de suas cores e texturas.

Foi elaborado um mapa de sol e sombra para indicar onde seria possível retornar com o plantio de grama. No Relatório não consta a existência de nenhuma espécie de grama, porém nas fotos analisadas, esta vegetação era muito freqüente. A espécie indicada foi a grama-batatais (Paspalum notatum), grama existente no Campo de Santana e Quinta da Boa Vista, nativa do Brasil e portanto, a mais acessível a Glaziou na época de implantação do projeto; resistente ao pisoteio, à seca, a solos pobres e tolerante a meia-sombra. Para as áreas sombreadas as plantas indicadas foram: Callisia repens, Ophiopogon japonicus, Ruellia brevifolia, Lycianthes asarifolia e Tradescantia fluminensis que, no entanto, não constam no citado Relatório.

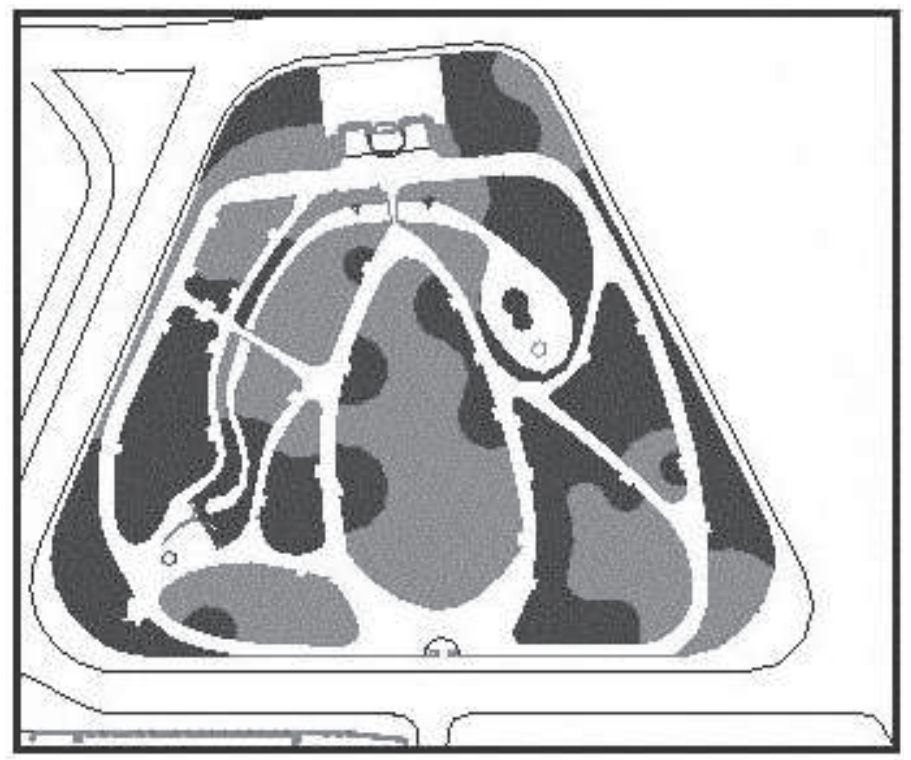

Figura 8: Planta esquemática indicando as áreas de sol (manchas claras) e as áreas de sombra (manchas escuras)

Crédito: Acervo da autora 
Devido aos inúmeros imprevistos ocorridos durante a obra, o plantio da vegetação de cobertura de sombra foi substituído pela fiscalização por grama-batatais na maior parte do parque e grama-esmeralda em frente à Fonte dos Amores. Naturalmente, devido a pouca resistência da grama a áreas sombreadas, esta vegetação irá morrer rapidamente, porém o compromisso dos gestores do Passeio Público foi o de executar o plantio indicado pelo Grupo Trabalho tão logo fosse possível.

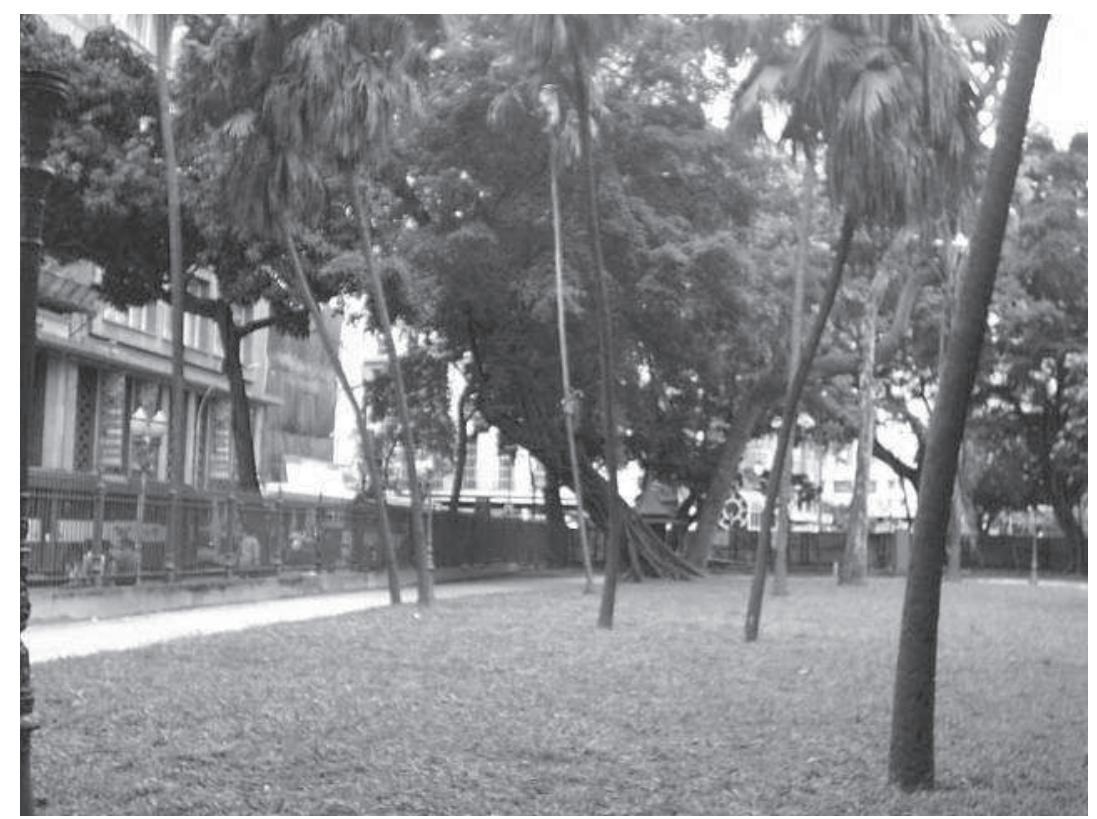

Figura 9: Plantio de grama-batatais nas áreas ensolaradas

Crédito: Foto da autora

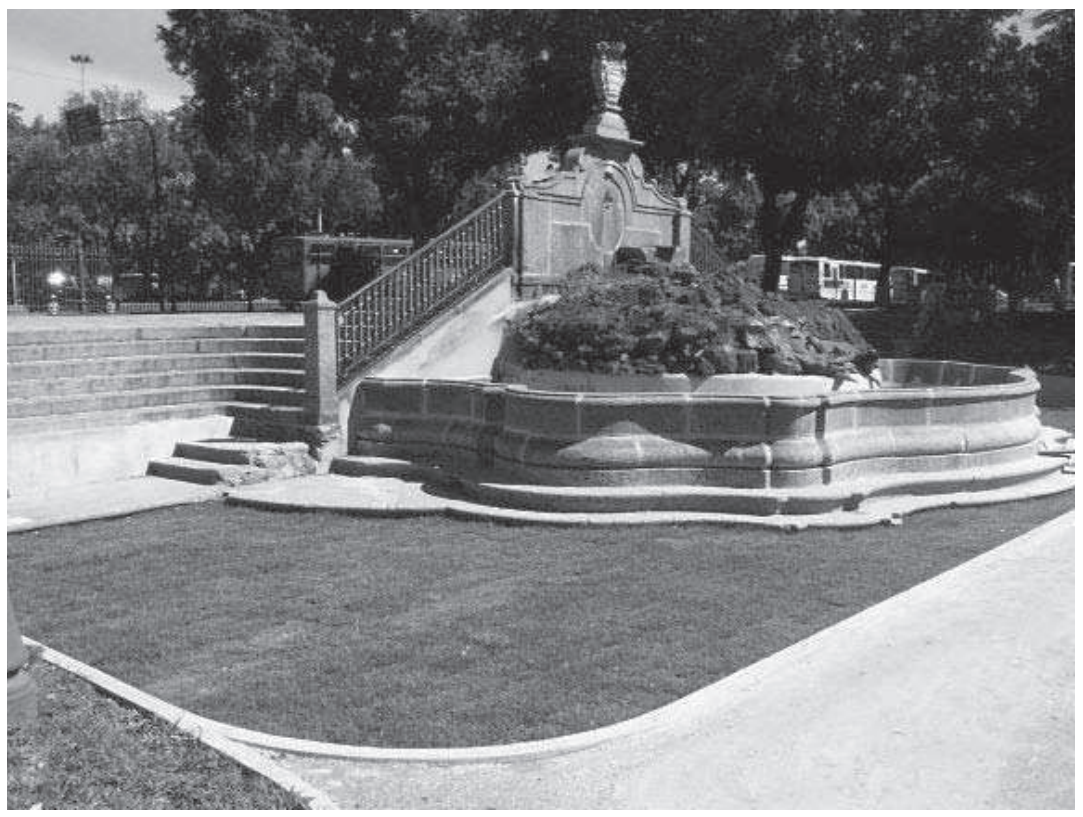

Figura 10: Plantio de grama esmeralda diante da Fonte dos Amores Crédito: Foto da autora

\section{Considerações finais}

O plano de manejo da vegetação do Passeio Público está intimamente ligado aos conhecimentos históricos, estéticos, técnicos, políticos, adquiridos pelo Grupo de Trabalho que orientou os trabalhos, até o momento dessa execução. Na realidade, as sugestões apresentadas sugerem uma construção cultural conceitual de um momento particular (o momento que a obra estava sendo 
realizada), levando em consideração as pesquisas e experiências profissionais dos integrantes do Grupo. A proposta para a reconstrução paisagística do Passeio Público, no que se refere a vegetação, foi fruto de um momento específico que, com o passar dos anos, poderá ser ratificada ou retificada. Portanto, nesta linha de pensamento, a definição do que preservar, retirar e replantar é, acima de tudo, uma decisão cultural baseada nas afirmações do presente.

Todo jardim histórico acumula informações que nos revelam o passado político, econômico, agrícola, botânico e urbano. É ao mesmo tempo uma obra de arte e um documento. Quando um jardim histórico encontra-se mal conservado, impossibilita o cidadão de conhecer um pouco mais da sua cultura. Os trabalhos de restauração dos jardins históricos devem expor e valorizar as características singulares, que permitem que esse espaço seja qualificado como obra de arte, sem prejudicar o valor documental que a passagem do tempo deixou escrito nesse lugar. Recuperar a imagem simbólica dos jardins históricos e seu testemunho cultural no desenvolvimento de uma região é reescrever a história das sociedades por um viés ainda pouco percorrido no Brasil.

\section{Notas}

(1) A versão integral deste artigo foi publicada junto com outras contribuições sobre a história e as obras de restauração do Passeio Público do Rio de Janeiro na revista Leituras Paisagísticas: teoria e práxis. Rio de Janeiro: EBA/ UFRJ, 2006. v. 1. (número temático denominado: (Re)construindo a paisagem do Passeio Público: historiografia e práticas projetuais).

(2) TRINDADE, Jeanne Almeida da. Campo de Santana: um patrimônio cultural carioca. Rio de Janeiro: PROARQ/ FAU/UFRJ, 2000. (Dissertação de Mestrado), p.43.

(3) Carta de Florença, maio de 1981. Cartas Patrimoniais. Brasília: IPHAN, 1995 (Caderno de Documentos, n³).

(4) Id.

(5) Id.

(6) FARAH, Ivete Mello Calil . Arborização pública e desenho urbano na cidade do Rio de Janeiro: a contribuição de Roberto Burle Marx. Rio de Janeiro: PROURB/FAU/UFRJ, 1997 (Dissertação de Mestrado), p.27-28.

(7) Op. cit.

(8) Op.cit.

(9) Op.cit.

(10) Op.cit.

\section{Bibliografia}

CARTAS PATRIMONIAIS. Caderno de Documentos. Brasília: Iphan, n. 3, 1995.

JOURNAL SCIENTIFIQUE. Jardins et sites historiques. Madri: ICOMOS, 1993.

VILAS BOAS, Naylor Barbosa. O passeio público do Rio de Janeiro: Análise histórica através da percepção do espaço. 2000. 153 p. Dissertação (Mestrado) - Universidade Federal do Rio de Janeiro, Rio de Janeiro: PROARQ/FAU, 2000.

TERRA, Carlos Gonçalves. Os jardins no Brasil do século XIX: Glaziou revisitado. Rio de Janeiro: EBA/UFRJ, 1993.

TRINDADE, Jeanne Almeida da. Campo de Santana: Um patrimônio cultural carioca. 2000. 208 p. Dissertação (Mestrado) - Universidade Federal do Rio de Janeiro, Rio de Janeiro: PROARQ/FAU, 2000. 